\title{
che?
}

\section{Programas para as juventudes cearenses no Plano Plurianual 2016-2019 do governo estadual}

\section{Bárbara Imaculada Araújo de Oliveira}

Bacharel em Gestão de Políticas Públicas pela Universidade Federal do Ceará - UFC

barbara.oliveira.gpp@gmail.com

https://orcid.org/0000-0002-8789-3483

\section{Julio Alfredo Racchumi Romero}

Doutor em Demografia pela Universidade Federal de Minas Gerais UFMG

Professor da Universidade Federal do Ceará - UFC

jarrest@gmail.com

https://orcid.org/0000-0003-3004-0647

\section{Resumo}

O objetivo deste artigo é mapear os programas para as juventudes do Plano Plurianual (PPA) 2016-2019 do Governo do Estado do Ceará e classificá-los dentro dos seguintes parâmetros: a) Ressocializador; b) Preparatório; ou c) Empoderamento. A última versão do Anexo I do PPA 2016-2019 (Demonstrativo de Temas Estratégicos e Programas) apresenta programas com enfoque juvenil em 12 de seus 31 temas estratégicos, nos quais foram mapeados 18 programas. Estes são de responsabilidade de 12 das 27 secretarias do governo estadual. Eis a classificação dos 18 programas mapeados: a) 1 tem caráter "Ressocializador"; b) 8 têm caráter "Preparatório"; e c) 9 têm caráter de "Empoderamento". Por fim, o PPA 2016-2019 apresenta como o Governo do Estado do Ceará vem empreendendo esforços não só para preparar os jovens para sua entrada no mercado de trabalho, mas, também, para empoderá-los por meio de programas que concedam garantias básicas e democratizem seu acesso a temas estratégicos (como esporte e cultura).

Palavras-chave juventudes; programas para as juventudes; plano plurianual;

estado do ceará.

Conhecer: debate entre o público e o privado

2020, Vol. 10, no 25

ISSN 2238-0426

DOI https://doi.org/10.32335/2238-0426.2020.10.25.3296

Licença Creative Commons Atribuição (CC BY 4.0)

Data de submissão 28 mai 20

Data de publicação 03 ago 20 


\title{
Ceará's youth programs in the 2016-2019 state government's pluriannual plan
}

\begin{abstract}
This article aims to map youth programs in the Ceará State Government's 2016-2019 Pluriannual Plan (PAP) and classify them within the following parameters: a) Resocializing; b) Preparatory; or c) Empowering. The latest version of Annex I of the 2016-2019 PAP (Statement of Strategic Themes and Programs) presents programs with a youth focus on 12 out of its 31 strategic themes, where 18 programs were mapped. They are up to 12 out of the 27 state government departments. This is the classification of the 18 programs mapped: a) 1 is 'Resocializing;' b) 8 are 'Preparatory;' and c) 9 are 'Empowering.' Finally, the 2016-2019 PAP presents how the Ceará State Government has been making efforts not only to prepare young people for their entry into the labor market, but also to empower them through programs that provide primary guarantees and democratize their access to strategic themes (such as sports and culture).
\end{abstract}

Key words youths; youth programs; pluriannual plan; state of ceará.

\section{Programas para la juventud de Ceará en el Plan Plurianual 2016-2019 del gobierno del estado}

\section{Resumen}

Este artículo tiene como objetivo mapear los programas para la juventud en el Plan Plurianual (PPA) 2016-2019 del Gobierno del Estado de Ceará y clasificarlos dentro de los siguientes parámetros: a) Resocialización; b) Preparatorio; o c) Empoderamiento. La última versión del Anexo I del PPA 2016-2019 (Declaración de Temas Estratégicos y Programas) presenta programas con un enfoque juvenil en 12 de sus 31 temas estratégicos, donde se mapearon 18 programas. Estos son responsabilidades de 12 de las 27 secretarías del gobierno del estado. Esta es la clasificación de los 18 programas mapeados: a) 1 tiene un carácter "Resocializador”; b) 8 tienen un carácter "Preparatorio"; y c) 9 tienen un carácter de "Empoderamiento". Finalmente, el PPA 20162019 presenta cómo el Gobierno del Estado de Ceará ha estado haciendo esfuerzos no solo para preparar a los jóvenes para su ingreso al mercado laboral, sino también para empoderarlos a través de programas que brindan garantías básicas y democratizan su acceso a temas estratégicos (como deporte y cultura).

Palabras clave juventud; programas para la juventud; plan plurianual; estado de ceará.

\section{Programmes pour la jeunesse du Ceará dans le Plan Pluriannuel 2016-2019 du gouvernement de l'état}

\section{Résumé}

Cet article vise à cartographier les programmes pour la jeunesse du Plan Pluriannuel (PPA) 2016-2019 du Gouvernement de l'État du Ceará et à les classer dans les paramètres suivants: a) Re-socialiseur; b) Préparatoire; ou c) Autonomisation. La dernière version de l'Annexe I du PPA 2016-2019 (Déclaration des Thèmes et Programmes Stratégiques) présente des programmes axés sur les jeunes dans 12 de ses 31 thèmes stratégiques, où 18 programmes ont été cartographiés. Telles sont les responsabilités de 12 des 27 secrétaires du gouvernement de l'état. Voici la classification des 18 programmes cartographiés: a) 1 a un caractère de " Re-socialisation »; b) 8 ont un caractère « Préparatoire »; et c) 9 ont un caractère de " Autonomisation ». Enfin, le PPA 2016-2019 présente comment le Gouvernement de l'État du Ceará a déployé des efforts non seulement pour préparer les jeunes à leur entrée sur le marché du travail, mais aussi pour les autonomiser grâce à des programmes qui offrent des garanties primaires et démocratisent leur accès à des thèmes stratégiques (telles que le sport et la culture).

Mots-clés ljeunesse; programmes pour la jeunesse; plan pluriannuel; état du ceará. 


\section{Introdução}

Entre os anos de 2007 e 2017, a taxa de mortalidade violenta juvenil' seguiu em ritmo de crescimento no Brasil, levando o país a uma taxa superior a 10 homicídios por 100 mil habitantes - considerada pela Organização Mundial da Saúde (OMS) um patamar epidêmico (Ferreira, Constantino, Souza, Pitta, \& Dini, 2010). Em 2017, a taxa brasileira de homicídio juvenil era de 69,9 por 100 mil habitantes (Instituto de Pesquisa Econômica Aplicada [Ipea] \& Fórum Brasileiro de Segurança Pública [FBSP], 2019). Não indo na contramão dos dados nacionais, as taxas cearenses também cresceram nesse período, alcançando 140,2 por 100 mil habitantes em 2017 - número que deixa o Estado do Ceará no segundo lugar nacional entre os estados com as piores taxas, ficando atrás apenas do Rio Grande do Norte, que detinha uma taxa de 152,3 (Figura 1).

Figura 1 Série histórica de homicídios juvenis no Estado do Ceará (2007-2017).

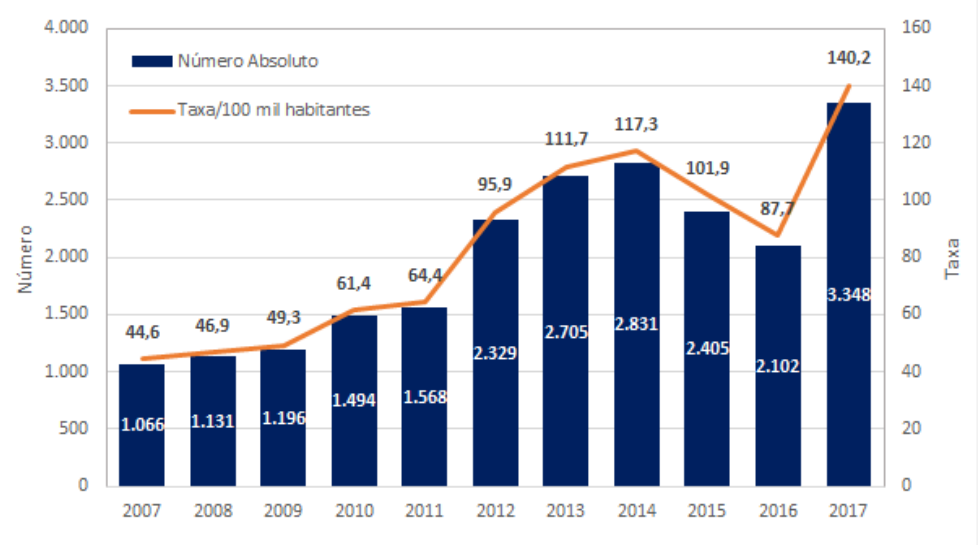

Fonte: Ipea e FBSP (2019).

Acompanhando a evolução das mortes juvenis no Ceará, visualizamos na Figura 1 o número absoluto das mortes juvenis por homicídio e sua taxa, ano a ano, no período de 2007 a 2017. Houve crescimento nos últimos anos, o que tem chamado a atenção de gestores e de pesquisadores da segurança pública no país. No acumulado dos 10 anos, o estado perdeu 22.220 jovens. Tal fato mostra que houve expressivo crescimento de $214,1 \%$ no número de homicídios no Ceará durante essa década. No último ano da série foi registrado aumento de 59,3\% em relação ao ano anterior.

Segundo Braga, Silva e Martins (2012) os homicídios juvenis passaram a se intensificar a partir dos anos 1980, quando a mortalidade juvenil se depara com uma transição -

1 De acordo com a Lei n. 12.852 (Estatuto da Juventude, 2013), são consideradas “jovens” as pessoas com idade entre 15 e 29 anos.

CONHECER: DEBATE ENTRE O PÚBLICO E O PRIVADO. V. 10 № 25/2020.2 
enquanto há diminuição dos números de morte por causas naturais ${ }^{2}$, inicia-se uma curva crescente de morte por causas externas ${ }^{3}$. A diminuição da mortalidade juvenil por causas naturais deveu-se a melhorias nas condições de vida dos brasileiros nos últimos anos, a partir de investimentos do Estado, principalmente no sistema de saúde, no saneamento básico e na educação (Waiselfisz, 2015). Ao mesmo tempo que esses números melhoraram, o país viu seus números de homicídios crescerem e passarem a configurar a principal causa de mortalidade externa de jovens já nos anos 1990 (Waiselfisz, 2015).

Os números da mortalidade juvenil se concentram em áreas socialmente vulneráveis, marcadas pelo difícil acesso dos jovens a políticas públicas como as voltadas a educação, trabalho, cultura e lazer. Minayo e Souza (1999) apontam o perfil preponderante das vítimas da mortalidade violenta no Brasil, caracterizadas como homens jovens, negros e periféricos. Essas vítimas apresentam, ainda, baixa escolarização e baixa qualificação profissional. Isso torna necessário reverter esse quadro por meio de políticas públicas estruturadas, articuladas e com efeitos duradouros, uma vez que o inverso disso já não é aceitável (Abramovay, 2002).

Na construção social, histórica e cultural do conceito de juventude, 2 visões têm sido preponderantes ao longo do debate. A primeira compreende as juventudes como fase da vida (Pais, 1990), resumindo-se a termos etários. Já a segunda apresenta as juventudes como um grupo plural (Pais, 1990), caraterizado por suas multiplicidades e diferenças.

Este artigo parte da junção dessas 2 visões, isto é, vê a juventude para além de uma fase delimitada em termos etários, considerando-a um grupo permeado por diversidade e múltiplas culturas, que distinguem e assemelham as juventudes a partir de suas particularidades e de seus variados modos de ser.

Mostra-se fundamental investir na pluralidade das juventudes para que elas superem suas vulnerabilidades e ampliem seu capital social e cultural (Abramovay, 2002), posto que viabilizar o acesso dos jovens a bens, serviços e diretos é um ponto relevante para superar a violência que permeia a vida juvenil (Braga et al., 2012) e permitir que eles transponham sua vulnerabilidade social (Abramovay, 2002).

Ademais, é crucial que as juventudes tenham espaços participativos para expressar seus sentimentos quanto às políticas públicas a elas destinadas, uma vez que, comungando com as ideias de Abramovay (2002), a efetividade das políticas públicas juvenis será maior na medida em que for permitida aos jovens sua atuação como protagonistas e problematizadores de sua própria vida. Diógenes (2012) pontua que se promete ao jovem um futuro melhor ao mesmo tempo que ele é privado de um presente melhor, o que reforça

\footnotetext{
2 "Óbito por causa natural é aquele cuja causa básica é uma doença ou estado mórbido" (Ministério da Saúde, 2009, p. 14).

3 "Óbito por causa externa (ou não natural) é aquele que decorre de lesão provocada por violência (homicídio, suicídio, acidente ou morte suspeita), qualquer que tenha sido o tempo entre o evento lesivo e a morte propriamente" (Ministério da Saúde, 2009, p. 15).
} 
a importância da existência de espaços participativos voltados aos jovens na construção das políticas públicas.

Em âmbito nacional, cabe destacar que o debate sobre políticas públicas para as juventudes se tornou mais incisivo e amplo a partir de 2005, com a criação da Secretaria Nacional de Juventude (SNJ); ele avançou ainda mais em 2010 e consagrou-se com a inclusão do termo juventude na Constituição da República Federativa do Brasil (CF, 1988); em 2013 houve outro avanço, ainda mais marcante: aprovou-se a Lei n. 12.852 (Estatuto da Juventude, 2013; B. I. A. Oliveira, 2019). Desse modo, observa-se uma crescente preocupação e ampliação de locais e mecanismos que possibilitem aos jovens passarem a atuar como cidadãos de direito, o que vai ao encontro das preocupações de Abramovay (2002) e Diógenes (2012).

Os estudos de Aquino (2009) e Alves e Barbalho (2014) ressaltam as interpretações que os jovens vão recebendo em cada contexto de sua vida. Aquino (2009) apresenta os jovens de acordo com 2 parâmetros: a) o primeiro traz os jovens como problema, e assim, as políticas públicas destinadas a eles seriam de caráter natureza ressocializadora; e b) o segundo apresenta os jovens como indivíduos em preparação para a vida adulta, para os quais se devem fornecer políticas públicas de natureza preparatória. Por sua vez, Alves e Barbalho (2014) reafirmam as ideias de Aquino (2009) e acrescentam um novo parâmetro, segundo o qual os jovens são tidos como sujeitos empoderados, o que leva à necessidade das políticas públicas juvenis Ihes atribuírem protagonismo, criatividade e inclusão social.

Com base nesses 3 parâmetros, o objetivo deste artigo é:

- Mapear os programas para as juventudes do Plano Plurianual (PPA) 2016-2019

do Governo do Estado do Ceará e classificá-los dentro dos parâmetros estabelecidos por Aquino (2009) e Alves e Barbalho (2014): a) Ressocializador; b) Preparatório; ou c) Empoderamento.

Além desta introdução, o texto se divide em 3 seções: a) metodologia; b) resultados e discussão; e c) considerações finais.

\section{Metodologia}

Este estudo se caracteriza como exploratório, porque tal modalidade de pesquisa viabiliza o estabelecimento de maior aproximação com o objeto (Gil, 1991) para, assim, identificá-lo, sistematizá-lo e classificá-lo.

Já a abordagem adotada para alcançar o objetivo proposto foi a qualitativa, uma vez que possibilita a pormenorização dos fenômenos para compreender os processos a partir de seu contexto (Galvão, Pluye, \& Ricarte, 2017).

Nosso recorte de análise categoriza as juventudes dentro do recorte etário estabelecido pelo Estatuto da Juventude (2013), ou seja, indivíduos com idade entre 15 
e 29 anos (Brasil, 2013). Os indivíduos com idade entre 15 e 18 anos são considerados, conjuntamente, adolescentes (Estatuto da Juventude, 2013).

O procedimento adotado para analisar o documento governamental consiste em pesquisa documental (Gil, 1991). Os programas mapeados foram aqueles que especificaram que seu público-alvo abrangia os jovens - eles poderiam apresentar ações específicas para os jovens ou incluí-los em suas ações globais. Compreende-se que os programas que caracterizam o público-alvo de modo genérico como "População do Estado do Ceará", "População em geral" e outros sinônimos também englobam os jovens, no entanto, elas não constituíram objetos deste estudo.

Vale ressaltar que um PPA, segundo a CF (1988), é um instrumento de planejamento que estabelece as diretrizes, os objetivos e as metas da administração pública.

Após a identificação dos programas dispostos no PPA do Ceará com foco nas juventudes, partiu-se para sua sistematização. Em uma primeira etapa, eles foram sistematizados por: a) tema estratégico; b) secretaria responsável; e c) objetivo.

A segunda etapa visou a classificá-los de acordo com os parâmetros estabelecidos por Aquino (2009) e Alves e Barbalho (2014). Um programa recebe a etiqueta "Ressocializador" quando enfoca jovens que já tiveram envolvimento com drogas ou criminalidade. A etiqueta "Preparatório" foi atribuída aos programas que ofertam aos jovens capacitação e inserção no mercado de trabalho. Já a etiqueta "Empoderamento" foi para os programas por meio dos quais os jovens assumem protagonismo.

\section{Resultados e discussão}

Esta seção se organiza em 2 subseções:

1. A primeira apresenta os programas destinados às juventudes no PPA 2016-2019 do Estado do Ceará; e

2. A segunda os classifica dentro dos grupos de programas: a) Ressocializador; b) Preparatório; e c) Empoderamento.

\section{Programas cearenses com enfoque na juventude no Plano}

\section{Plurianual 2016-2019}

A última versão do Anexo I do PPA 2016-2019 - Demonstrativo de Temas Estratégicos e Programas (Ceará, 2018) - apresenta programas com enfoque juvenil em 12 de seus 31 temas estratégicos, nos quais se mapearam 18 programas (Ceará, 2018). Os programas encontrados são de responsabilidade de 12 das 27 secretarias do governo estadual ${ }^{4}$, quais

4 A nomenclatura e a divisão das secretarias segue o organograma vigente na época do PPA 2016-2019. 
sejam: a) Secretaria da Fazenda (SEFAZ); b) Secretaria do Trabalho e Desenvolvimento Social (STDS); c) Secretaria da Justiça (SEJUS); d) Gabinete do Governador (GABGOV); e) Secretaria do Desenvolvimento Agrário (SDA); f) Secretaria do Desenvolvimento Econômico (SDE); g) Secretaria da Educação (SEDUC); h) Secretaria da Ciência, Tecnologia e Educação Superior (SECITECE); i) Secretaria da Cultura (SECULT); j) Secretaria da Saúde (SESA); k) Secretaria do Esporte (SESPORTE); e I) Secretaria da Segurança Pública e Defesa Social (SSPDS).

A Tabela 1 sistematiza os programas mapeados, indicando o tema estratégico, a secretaria responsável e seu objetivo.

Tabela 1 Sistematização dos programas com enfoque juvenil no Plano Plurianual 2016-2019

\begin{tabular}{|c|c|c|c|}
\hline Programa & $\begin{array}{c}\text { Tema } \\
\text { Estratégico }\end{array}$ & $\begin{array}{c}\text { Secretaria } \\
\text { Responsável }\end{array}$ & Objetivo \\
\hline $\begin{array}{l}\text { Educação Fiscal } \\
\text { e Cidadania }\end{array}$ & Gestão Fiscal & SEFAZ & $\begin{array}{l}\text { Desenvolver ações para esclarecer os cidadãos sobre } \\
\text { a função social dos tributos, a gestão fiscal do Estado } \\
\text { e de sua responsabilidade no controle da aplicação } \\
\text { desses recursos, por meio do exercício da cidadania, } \\
\text { buscando, assim, a construção de uma sociedade mais } \\
\text { livre, justa e solidária. }\end{array}$ \\
\hline $\begin{array}{l}\text { Proteção Social } \\
\text { Especial }\end{array}$ & Assistência Social & STDS & $\begin{array}{l}\text { Garantir a oferta de serviços de proteção social especial } \\
\text { no âmbito do Sistema Único de Assistência Social - SUAS } \\
\text { para famílias e indivíduos em situação de risco pessoal } \\
\text { e social por violação de direitos e/ou rompimento de } \\
\text { vínculos familiares e comunitários. }\end{array}$ \\
\hline $\begin{array}{c}\text { Proteção Social } \\
\text { Básica }\end{array}$ & Assistência Social & STDS & $\begin{array}{l}\text { Assegurar a implementação do Sistema Único de } \\
\text { Assistência Social no Ceará, apoiando a gestão municipal } \\
\text { e a rede socioassistencial dos serviços, programas, } \\
\text { projetos e benefícios da Proteção Social Básica. }\end{array}$ \\
\hline $\begin{array}{l}\text { Garantia dos } \\
\text { Direitos Humanos e } \\
\text { Cidadania }\end{array}$ & $\begin{array}{l}\text { Inclusão Social e } \\
\text { Direitos Humanos }\end{array}$ & SEJUS & $\begin{array}{l}\text { Atender a garantia dos direitos humanos e cidadania, } \\
\text { ampliando a visibilidade e a acessibilidade dos serviços } \\
\text { oferecidos a sociedade. }\end{array}$ \\
\hline $\begin{array}{c}\text { Promoção e } \\
\text { Defesa dos Direitos } \\
\text { Humanos }\end{array}$ & $\begin{array}{l}\text { Inclusão Social e } \\
\text { Direitos Humanos }\end{array}$ & GABGOV & $\begin{array}{l}\text { Contribuir para a efetividade das políticas públicas } \\
\text { referentes à promoção e defesa dos direitos dos } \\
\text { segmentos vulneráveis. }\end{array}$ \\
\hline $\begin{array}{l}\text { Proteção e } \\
\text { Promoção dos } \\
\text { Direitos de } \\
\text { Adolescentes } \\
\text { em Atendimento } \\
\text { Socioeducativo }\end{array}$ & $\begin{array}{l}\text { Inclusão Social e } \\
\text { Direitos Humanos }\end{array}$ & STDS & $\begin{array}{l}\text { Prestar atendimento integral ao adolescente em } \\
\text { cumprimento de medida socioeducativa privativa/ } \\
\text { restritiva de liberdade, fortalecendo sua reinserção } \\
\text { sociofamiliar e comunitária. }\end{array}$ \\
\hline $\begin{array}{l}\text { Promoção da } \\
\text { Segurança } \\
\text { Alimentar e } \\
\text { Nutricional }\end{array}$ & $\begin{array}{l}\text { Segurança } \\
\text { Alimentar e } \\
\text { Nutricional }\end{array}$ & SDA & $\begin{array}{l}\text { Contribuir para a garantia da segurança alimentar e } \\
\text { nutricional da população, priorizando os grupos com } \\
\text { vulnerabilidade social, com o acesso a alimentos em } \\
\text { qualidade e quantidade satisfatória. }\end{array}$ \\
\hline
\end{tabular}




\begin{tabular}{|c|c|c|c|}
\hline Programa & $\begin{array}{c}\text { Tema } \\
\text { Estratégico }\end{array}$ & $\begin{array}{c}\text { Secretaria } \\
\text { Responsável }\end{array}$ & Objetivo \\
\hline $\begin{array}{l}\text { Inclusão e } \\
\text { Desenvolvimento } \\
\text { do Trabalhador }\end{array}$ & Trabalho e Renda & STDS & $\begin{array}{l}\text { Viabilizar maiores e melhores oportunidades de } \\
\text { qualificação profissional, colocação/recolocação no } \\
\text { emprego, inserção produtiva e incremento de renda aos } \\
\text { trabalhadores cearenses. }\end{array}$ \\
\hline $\begin{array}{l}\text { Empreendedorismo } \\
\text { e Protagonismo } \\
\text { Juvenil }\end{array}$ & Empreendedorismo & SDE & $\begin{array}{l}\text { Promover e ampliar a educação e a cultura } \\
\text { empreendedora no Estado do Ceará. }\end{array}$ \\
\hline $\begin{array}{l}\text { Inclusão e Equidade } \\
\text { na Educação }\end{array}$ & Educação Básica & SEDUC & $\begin{array}{l}\text { Garantir Escola como espaço educador sustentável, } \\
\text { inclusiva, que respeite às diversidades e promova a } \\
\text { equidade no padrão de acesso, nas condições de oferta, } \\
\text { de permanência e nos resultados de aprendizagem, } \\
\text { atendendo adequadamente aos educandos } \\
\text { com necessidades especiais, com características } \\
\text { diferenciadas e/ou àqueles pertencentes às populações } \\
\text { vulneráveis em articulação intersetorial. }\end{array}$ \\
\hline $\begin{array}{c}\text { Acesso e } \\
\text { Aprendizagem das } \\
\text { Crianças e Jovens } \\
\text { na Idade Adequada } \\
\end{array}$ & Educação Básica & SEDUC & $\begin{array}{l}\text { Fortalecimento da Educação Infantil e elevação do nível } \\
\text { de alfabetização e de aprendizagem das crianças e } \\
\text { jovens na idade adequada do Ensino Fundamental. }\end{array}$ \\
\hline $\begin{array}{c}\text { Gestão e } \\
\text { Desenvolvimento } \\
\text { da Educação Básica } \\
\end{array}$ & Educação Básica & SEDUC & $\begin{array}{l}\text { Garantir as condições para o bom funcionamento } \\
\text { da gestão organizacional e pedagógica, focadas na } \\
\text { permanência, no fluxo e na aprendizagem dos alunos. }\end{array}$ \\
\hline $\begin{array}{l}\text { Ensino Integrado } \\
\text { à Educação } \\
\text { Profissional }\end{array}$ & $\begin{array}{l}\text { Educação } \\
\text { Profissional }\end{array}$ & SEDUC & $\begin{array}{l}\text { Atender às necessidades do mundo do trabalho, } \\
\text { contribuindo para o desenvolvimento do Estado, para } \\
\text { a inserção dos estudantes no mercado de trabalho e no } \\
\text { Ensino Superior. }\end{array}$ \\
\hline $\begin{array}{c}\text { Desenvolvimento } \\
\text { da Educação } \\
\text { Profissional nos } \\
\text { Níveis: Formação } \\
\text { Inicial e Continuada, } \\
\text { Técnico e Tecnol } \\
\end{array}$ & $\begin{array}{l}\text { Educação } \\
\text { Profissional }\end{array}$ & SECITECE & $\begin{array}{l}\text { Contribuir para a qualificação de jovens e adultos } \\
\text { aumentando suas oportunidades de emprego e renda. }\end{array}$ \\
\hline $\begin{array}{l}\text { Promoção do } \\
\text { Acesso e Fomento } \\
\text { à Produção e } \\
\text { Difusão da Cultura } \\
\text { Cearense }\end{array}$ & Cultura & SECULT & $\begin{array}{l}\text { Democratizar o acesso aos bens, serviços e o uso de } \\
\text { equipamentos e espaços culturais, bem como fomentar } \\
\text { os processos de criação, produção, difusão, formação, } \\
\text { pesquisa, intercâmbio e fruição das expressões } \\
\text { artísticas e culturais cearenses, com ênfase nas políticas } \\
\text { afirmativas e de acessibilidade para promoção da } \\
\text { cidadania cultural e desenvolvimento da economia da } \\
\text { cultura no Estado. }\end{array}$ \\
\hline $\begin{array}{l}\text { Atenção à Saúde } \\
\text { Integral e de } \\
\text { Qualidade }\end{array}$ & Saúde & SESA & $\begin{array}{l}\text { Promover a integralidade e o aprimoramento da } \\
\text { política da atenção básica, especializada, ambulatorial } \\
\text { e hospitalar. }\end{array}$ \\
\hline $\begin{array}{l}\text { Esporte e Lazer } \\
\text { Para a População }\end{array}$ & Esporte e Lazer & SESPORTE & $\begin{array}{l}\text { Promover a saúde, a cidadania e a integração da } \\
\text { população cearense na convivência social. }\end{array}$ \\
\hline
\end{tabular}




\begin{tabular}{c|c|c|l}
\hline Programa & $\begin{array}{c}\text { Tema } \\
\text { Estratégico }\end{array}$ & $\begin{array}{c}\text { Secretaria } \\
\text { Responsável }\end{array}$ & Objetivo \\
\hline $\begin{array}{c}\text { Segurança Pública } \\
\text { Cidadã }\end{array}$ & Segurança Pública & SSPDS & $\begin{array}{l}\text { Aumentar a sensação de segurança e a credibilidade } \\
\text { dos órgãos da segurança pública perante a população } \\
\text { cearense. }\end{array}$ \\
\hline
\end{tabular}

Nota: As palavras-chave dos objetivos dos programas estão destacadas em itálico.

Fonte: Ceará (2018).

Considerando o tema estratégico Gestão Fiscal, a Tabela 1 apresenta o programa Educação Fiscal e Cidadania, que tem os alunos de todos os níveis de ensino como públicoalvo e sua principal iniciativa é a "realização de atividades sobre o tema Educação Fiscal para o ensino fundamental e médio e fomento à pesquisa e à extensão universitária" (Ceará, 2018, p. 173). O programa se justifica pela noção de que o conhecimento da população sobre Gestão Fiscal contribuirá para uma relação harmônica entre Estado e sociedade, na qual ela manterá em dia suas obrigações tributárias.

No tema estratégico Assistência Social temos os seguintes programas: a) Proteção Social Especial; e b) Proteção Social Básica. O primeiro não apresenta nenhuma ação específica direcionada aos jovens, no entanto, eles estão inseridos no público-alvo do programa e a justificativa para tal decorre de seu foco ser proteger famílias e indivíduos que tiveram direitos violados e que se encontram em situação de risco social e pessoal. Já o segundo: a) tem os jovens em seu público-alvo; b) justifica-se na implementação e no fortalecimento do Sistema Único da Assistência Social (SUAS); e c) apresenta uma iniciativa focalizada nos jovens - qual seja, "apoio ao atendimento às crianças, adolescentes, jovens e suas famílias em situação de risco pessoal e social” (Ceará, 2018, p. 61).

O tema estratégico Inclusão Social e Direitos Humanos apresenta os seguintes programas: a) Garantia dos Direitos Humanos e Cidadania; b) Promoção e Defesa dos Direitos Humanos; e c) Proteção e Promoção dos Direitos de Adolescentes em Atendimento Socioeducativo. Os 2 primeiros programas não apresentam iniciativas específicas para 0 público jovem, no entanto, ele está incluído dentro do público-alvo global deles. O primeiro se justifica pela missão institucional da SEJUS de "promover o pleno exercício da cidadania e a defesa dos direitos humanos inalienáveis" (Ceará, 2018, p. 65). O segundo se justifica pela proteção da população mais vulnerável do estado. Já o terceiro programa se justifica pela responsabilidade do estado de manter o sistema socioeducativo - todas as iniciativas são focadas nas juventudes. No entanto, uma vez que se trata de um programa para o sistema socioeducativo, ele tem um recorte etário de 15 a 17 anos na faixa etária juvenil. Tal programa visa a implementar iniciativas de melhoria, ampliação e manutenção do sistema socioeducativo do estado, além de ofertar aos adolescentes em cumprimento de medidas socioeducativas projetos de formação e qualificação profissional. 
Para o tema estratégico Segurança Alimentar e Nutricional se apresenta o programa Promoção da Segurança Alimentar e Nutricional, no qual o público jovem atendido consiste em estudantes de escolas públicas. Quanto às iniciativas, elas se dão no campo do suporte à produção e à aquisição dos alimentos. E sua justificativa se pauta pelo fato de que enquanto a agricultura familiar é a principal fonte de abastecimento alimentício do país, tem-se dificuldade de acesso a esses alimentos nos grupos mais vulneráveis, assim, as iniciativas desse programa procuram superar tal impasse.

No tema estratégico Trabalho e Renda temos o programa Inclusão e Desenvolvimento do Trabalhador. Ele se justifica pela preocupação com o aumento do desemprego, o qual é intensificado pelos avanços tecnológicos. O público-alvo do programa engloba jovens em busca do primeiro emprego. Apesar de não apresentar nenhuma ação específica para esse público, sua preocupação com os jovens é exposta na justificativa:

O desemprego da juventude é um fenômeno que tem preocupado bastante os governos, tendo em vista que o mesmo alcança uma taxa quase 3 vezes maior do que a do adulto, representando a rejeição do mercado por pessoas sem experiência profissional (Ceará, 2018, p. 96).

O tema estratégico Empreendedorismo apresenta o programa Empreendedorismo e Protagonismo Juvenil. O público-alvo consiste em empreendedores e potenciais empreendedores e esse programa se justifica pela deficiência observada no sistema de ensino regular e técnico, que inviabiliza atividades empreendedoras.

Para o tema estratégico Educação Básica temos 3 programas, todos com jovens como público-alvo.

O primeiro programa é o Inclusão e Equidade na Educação, o qual se justifica pela noção de que a universalização da educação básica passa pela redução das desigualdades e pela superação das exclusões sociais. Algumas de suas iniciativas são:

Qualificação da oferta de Educação de Jovens e Adultos para as pessoas que não concluíram a Educação Básica na idade própria, incluindo os privados de liberdade e as comunidades terapêuticas de adictos; Atendimento diferenciado para estudantes trabalhadores e demais segmentos vulneráveis à reprovação, ao abandono e à evasão escolar; Currículo e gestão diferenciada para escolas do campo, indígenas e quilombolas contemplando suas especificidades culturais e territoriais (Ceará, 2018, p. 119). 
O segundo programa é o Acesso e Aprendizagem das Crianças e Jovens na Idade Adequada, que engloba os jovens com idade entre 15 e 16 anos em todas as suas iniciativas. O programa se justifica pela melhoria do aprendizado e dos indicadores municipais de educação.

Já o terceiro programa é o Gestão e Desenvolvimento da Educação Básica, o qual se justifica pela necessidade de atuação conjunta de escola, família e sociedade. Uma de suas iniciativas é a "articulação curricular do Ensino Médio com as realidades territoriais, a educação científica, a convivência, o lazer, a arte, a pluralidade cultural, o empreendedorismo, o protagonismo e o mundo do trabalho" (Ceará, 2018, p. 123).

Já o tema estratégico Educação Profissional traz 2 programas, ambos com os jovens como público-alvo. O primeiro programa é o Ensino Integrado à Educação Profissional, o qual se justifica pela necessidade de qualificar a mão de obra cearense e pelos anseios dos jovens para ingressar no mercado de trabalho. É dentro desse programa que se encontram as Escolas Estaduais de Educação Profissional. O segundo programa é o Desenvolvimento da Educação Profissional, nos níveis: a) Formação Inicial e Continuada; b) Técnico; e c) Tecnológico. Ele apresenta como justificativa o compromisso do estado ofertar qualificação aos cidadãos que supram as exigências do mercado de trabalho.

No tema estratégico Cultura temos o programa Promoção do Acesso e Fomento à Produção e Difusão da Cultura, o qual se justifica pela ainda baixa ramificação da política cultural nas agendas governamentais e apresenta uma iniciativa com foco em jovens, qual seja: "ampliação ao acesso e inserção de jovens e crianças nas atividades culturais" (Ceará, 2018, p. 137).

O tema estratégico Saúde traz o programa Atenção à Saúde Integral e de Qualidade, o qual se justifica pela intenção de reduzir os vazios assistenciais com vistas a enfrentar os problemas de saúde que ainda persistem. Ele apresenta uma iniciativa com enfoque juvenil, qual seja: "realização de ações voltadas à saúde do adolescente" (Ceará, 2018, p. 147).

No tema estratégico Esporte e Lazer se encontra o programa Esporte e Lazer para a População, que engloba todas as faixas etárias da população e justifica-se pela noção de contribuir para o desenvolvimento integral dos cidadãos. Quanto às suas iniciativas, todas são de caráter universal, relativas à infraestrutura para as práticas de esporte e os ambientes de lazer.

Por último, o tema estratégico Segurança Pública apresenta o programa Segurança Pública Cidadã, o qual se justifica pelo estabelecimento de uma parceria entre a sociedade e as forças da segurança pública. Ele apresenta 4 iniciativas com enfoque juvenil:

Manutenção da oferta dos serviços voltados à preservação dos direitos das crianças, adolescentes, mulheres e minorias; Ampliação dos serviços voltados a preservação dos direitos das crianças, adolescentes, mulheres e minorias; 
Ampliação dos serviços de educação física, preventiva e social, com foco na juventude e na terceira idade; Realização de atividades esportivas, educativas e culturais para jovens da comunidade e familiares dos profissionais da segurança pública (Ceará, 2018, p. 164-165).

Em resumo, dentre as 12 secretarias estaduais nas quais foram mapeados programas com enfoque juvenil temos 10 secretarias que são responsáveis por apenas 1 programa cada (SEFAZ; SEJUS; GABGOV; SDA; SDE; SECITECE; SECULT; SESA; SESPORTE; SSPDS). Apenas a STDS e a SEDUC apresentam mais de 1 programa sob sua responsabilidade (4 programas cada).

A área temática Assistência Social apresenta 2 programas; a Inclusão Social e Direitos Humanos, 3; a Educação Básica, 3; a Educação Profissional, 2; e as demais, apenas 1 programa cada (Gestão Fiscal; Segurança Alimentar e Nutricional; Trabalho e Renda; Empreendedorismo; Cultura; Saúde; Esporte e Lazer; Segurança Pública).

\section{O foco dos programas para as juventudes cearenses no Plano Plurianual 2016-2019}

Realizada a sistematização dos programas, segue-se para a classificação deles quanto aos parâmetros ou grupos (Ressocializador; Preparatório; e Empoderamento) ${ }^{5}$. Não obstante, primeiro identificamos as palavras-chave dos objetivos de cada programa, isso porque será possível classificar cada grupo por meio delas e com apoio nas configurações e perspectivas dos programas. As palavras-chave foram utilizadas como modo de identificação, intepretação e aproximação daquilo que os programas oferecem para os alocar em cada grupo ou parâmetro. A Tabela 2 apresenta as palavras-chave de cada programa.

Tabela 2 Palavras-chave dos objetivos dos programas.

\begin{tabular}{l|l}
\hline \multicolumn{1}{c|}{ Programa } & \multicolumn{1}{c}{ Palavra-chave } \\
\hline Educação Fiscal e Cidadania & Esclarecer; Construção. \\
\hline Proteção Social Especial & Garantir; Proteção. \\
\hline Proteção Social Básica & Assegurar; Apoiando. \\
\hline Garantia dos Direitos Humanos e Cidadania & Atender a garantia; Ampliando. \\
\hline Promoção e Defesa dos Direitos Humanos & Contribuir para a efetividade; Promoção; Defesa. \\
\hline Proteção e Promoção dos Direitos de Adolescentes em & Prestar; Reinserção. \\
Atendimento Socioeducativo & \\
\hline
\end{tabular}

5 Os grupos utilizados para a classificação também são conhecidos como parâmetros, porque não é apenas um conjunto disposto por semelhanças, mas que considera características e valores entendidos como determinada circunstância ou perspectiva, considerado a partir das ideias de Aquino (2009) e Alves e Barbalho (2014). 


\begin{tabular}{l|l}
\hline \multicolumn{1}{c|}{ Programa } & \multicolumn{1}{c}{ Palavra-chave } \\
\hline Promoção da Segurança Alimentar e Nutricional & Contribuir para a garantia. \\
\hline Inclusão e Desenvolvimento do Trabalhador & Viabilizar; Oportunidades; Qualificação. \\
\hline Empreendedorismo e Protagonismo Juvenil & Promover; Ampliar; Empreendedora. \\
\hline Inclusão e Equidade na Educação & Garantir Escola; Aprendizagem. \\
\hline Acesso e Aprendizagem das Crianças e Jovens na Idade & Fortalecimento da Educação Infantil; Elevação do Ensino \\
Adequada & Fundamental. \\
\hline Gestão e Desenvolvimento da Educação Básica & Garantir funcionamento. \\
\hline Ensino Integrado à Educação Profissional & Atender; Trabalho. \\
\hline Desenvolvimento da Educação Profissional nos Níveis: & Contribuir; Qualificação. \\
Formação Inicial e Continuada, Técnico e Tecnol & \\
\hline Promoção do Acesso e Fomento à Produção e Difusão da & Democratizar; Fomentar. \\
Cultura Cearense & \\
\hline Atenção à Saúde Integral e de Qualidade & Promover. \\
\hline Esporte e Lazer Para a População & Promover. \\
\hline Segurança Pública Cidadã & Aumentar. \\
\hline
\end{tabular}

Fonte: Elaborada pelos autores.

O que se observa é que os programas destinados às juventudes cearenses no PPA 2016-2019 se estruturam, principalmente, em 2 grandes blocos: a) promover uma educação de qualidade, acompanhada pela inserção no mercado de trabalho; e b) assegurar direitos básicos, seguidos por tímida, mas crescente, democratização e promoção de acesso a outros programas fora do eixo educação-trabalho. Apesar dos altos índices de mortalidade juvenil, não se identificou nenhum programa que trata diretamente sobre o tema, no sentido de buscar reduzir tais números.

Apesar dos programas do eixo educação-trabalho se mostrarem fundamentais para a formação inicial dos jovens, é fundamental que os programas do segundo bloco sejam fortalecidos e ampliados. De acordo com R. F. V. Oliveira (2017), além das Políticas Públicas (programas) destinadas a proporcionar uma formação tradicional, os programas destinados às juventudes devem propiciar uma formação que conecte cultura, arte e esporte.

Antes de apresentar a classificação de cada programa, traça-se um breve panorama das principais questões que envolvem os grupos (a ser utilizado no procedimento de classificação, para compreender a perspectiva de cada um deles na sociedade). Partindo das conceituações teóricas de Aquino (2009) e Alves e Barbalho (2014), vale discutir o principal papel de cada categoria na sociedade e nas políticas públicas. O primeiro grupo, dos programas Ressocializadores, consiste naqueles que ressocializam os jovens em conflito com a lei, com a finalidade de retomarem uma vida saudável e darem continuidade ao seu desenvolvimento social e psicológico (Mantovani, 2009). O segundo grupo, dos programas Preparatórios, consiste naqueles que proporcionam oportunidades para uma formação educacional e profissional apropriada, gerando expectativas para o futuro após a conclusão 
dos estudos na escola ou na universidade. É importante ressaltar que, no atual contexto econômico e social, os empregos são cada vez mais raros e uma educação apropriada pode ajudar no desenvolvimento de uma trajetória profissional satisfatória, ao aumentar a chance dos jovens entrarem e permanecerem no mercado de trabalho (Guimarães \& Almeida, 2012). Por fim, grupo dos programas de Empoderamento, consiste naqueles por meio dos quais se analisam e se detectam as necessidades de um coletivo desfavorecido social, econômico, cultural, entre outros, com o intuito de proporcionar as ferramentas necessárias para que possam obter maior autonomia e diminuir sua vulnerabilidade. Nesse sentido, o protagonismo juvenil é um componente importante e reconhece-se que provoca transformações decisivas na realidade social, econômica, ambiental, cultural e política na qual se encontra inserido (Semicheche, Higa, \& Cabreira, 2012).

Os programas com enfoque juvenil do PPA 2016-2019 são identificados e classificados com base nos conceitos desses três grupos, apoiando-se nas palavras-chave para a alocação de cada programa nos grupos ou parâmetros definidos.

Os programas nos quais se identificou a palavra-chave reinserção foram classificados no primeiro grupo (Ressocializador). Os programas com palavras-chave como educação, trabalho, qualificação e empreendedor foram classificados no segundo grupo (Preparatório). E ficaram no terceiro grupo (Empoderamento) os programas que apresentavam palavraschave como proteção, garantia e defesa.

A Tabela 3 indica que, dentre os 18 programas mapeados, 1 tem caráter Ressocializador, 8 têm caráter Preparatório e 9 têm caráter de Empoderamento. 
Tabela 3 Classificação dos programas.

\begin{tabular}{|c|c|c|}
\hline Ressocializador & Preparatório & De empoderamento \\
\hline \multirow{9}{*}{$\begin{array}{l}\text { Proteção e Promoção dos Direitos } \\
\text { de Adolescentes em Atendimento } \\
\text { Socioeducativo. }\end{array}$} & Educação Fiscal e Cidadania; & Proteção Social Especial; \\
\hline & $\begin{array}{l}\text { Inclusão e Desenvolvimento do } \\
\text { Trabalhador; }\end{array}$ & Proteção Social Básica; \\
\hline & $\begin{array}{l}\text { Empreendedorismo e Protagonismo } \\
\text { Juvenil; }\end{array}$ & $\begin{array}{l}\text { Garantia dos Direitos Humanos e } \\
\text { Cidadania; }\end{array}$ \\
\hline & Inclusão e Equidade na Educação; & $\begin{array}{l}\text { Promoção e Defesa dos Direitos } \\
\text { Humanos; }\end{array}$ \\
\hline & $\begin{array}{l}\text { Acesso e Aprendizagem das Crianças e } \\
\text { Jovens na Idade Adequada; }\end{array}$ & $\begin{array}{l}\text { Promoção da Segurança Alimentar e } \\
\text { Nutricional; }\end{array}$ \\
\hline & $\begin{array}{l}\text { Gestão e Desenvolvimento da } \\
\text { Educação Básica; }\end{array}$ & $\begin{array}{l}\text { Promoção do Acesso e Fomento } \\
\text { à Produção e Difusão da Cultura } \\
\text { Cearense; }\end{array}$ \\
\hline & $\begin{array}{l}\text { Ensino Integrado à Educação } \\
\text { Profissional; }\end{array}$ & $\begin{array}{l}\text { Atenção à Saúde Integral e de } \\
\text { Qualidade; }\end{array}$ \\
\hline & 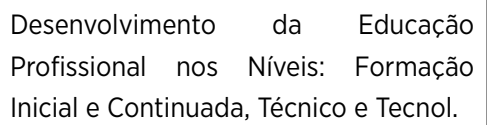 & Esporte e Lazer Para a População; \\
\hline & & Segurança Pública Cidadã. \\
\hline
\end{tabular}

Fonte: Elaborada pelos autores.

Analisando os programas a partir das palavras-chave destacadas em seus objetivos com vistas a classificá-los, observa-se que dentro do grupo Preparatório há predominância de palavras que orientam para uma atuação na formação dos jovens (programas educacionais) e para sua inserção e manutenção no mercado de trabalho de modo qualificado (programas de trabalho/empreendedorismo/qualificação). Guimarães e Almeida (2012) destacam que os jovens, devido à sua menor experiência, enfrentam maiores dificuldades no mercado de trabalho, um quadro que se torna mais complicado no Brasil devido à baixa escolaridade média e à baixa qualidade da educação de parte dos jovens, assim, são fundamentais as políticas públicas voltadas à universalização do ensino, à melhoria da qualidade da educação, à erradicação do trabalho infantil e aos incentivos de estrutura setorial de ocupação para os jovens.

Para o grupo Empoderamento se encontram palavras que ora orientam a garantia básica de direitos (programas de assistência social/segurança alimentar) ora orientam um(a) maior protagonismo e qualidade de vida dos jovens (programas de cultura/esporte/ saúde) e, ainda, há programas que visam a uma segurança pública com maior confiança entre jovens (sociedade) e as instituições competentes da área. No atual contexto, os jovens são cada vez mais chamados a interiorizar expectativas de autonomia, mas se deparam com menores possibilidades de materializá-la; em seus percursos de vida, eles encontram obstáculos para efetivar tal autonomia, principalmente aqueles que vivem em condições 
de vulnerabilidade. Esses empecilhos dificultam a qualificação profissional e pessoal e as políticas públicas se tornam imprescindíveis, sobretudo para construir estratégias subjetivas e sociais de protagonismo e autonomia (Silva \& Ximenes, 2019).

No que se refere ao grupo Ressocialização, o programa identificado orienta as ações quanto à organização de um sistema socioeducativo que atenda aos jovens de modo integral e promova sua reinserção social. Essa ação de governo, executada pela Superintendência do Sistema Estadual de Atendimento Socioeducativo (SEAS), realiza atendimentos nas Unidades da Proteção Social Especial a Adolescentes em Conflito com a Lei no Cumprimento de Medidas Socioeducativas. Essa ação deve garantir soluções para problemas que prejudicam não apenas os jovens, mas a sociedade como um todo. Nesse sentido, as instituições governamentais devem implementar políticas públicas inclusivas, que estimulem o desenvolvimento humano digno e a participação dos jovens na sociedade. Tal como assevera Manfroi (2016), referindo-se às políticas públicas de ressocialização, as quais devem ser capazes de promover valorização humana, aprendizado e perspectiva de inclusão social, além de fazer com que os programas socioeducativos deixem de ser um castigo ou o pagamento de um mal praticado e tornem-se um ambiente de educação, aprendizagem e preparação para o trabalho, possibilitando crescimento humano, intelectual, profissional e social.

\section{Considerações finais}

Para contribuir com o debate sobre os esforços realizados pelo poder público em relação à elaboração de programas para as juventudes no PPA 2016-2019 do Governo do Estado do Ceará, este artigo trouxe alguns aspectos relevantes para a discussão, ajudando a refletir sobre a direção dos programas voltados aos jovens cearenses. Assim, este estudo atingiu seu objetivo mapeando os programas para as juventudes do PPA 2016-2019 do governo estadual e classificando-os dentro dos parâmetros estabelecidos por Aquino (2009) e Alves e Barbalho (2014).

O modo como se apresenta a distribuição dos programas para as juventudes nos permite discutir dois pontos importantes. Primeiro, considerando a juventude um fenômeno múltiplo, plural e multidimensional (Pais, 1990), as políticas desenvolvidas e implementadas no PPA 2016-2019 podem estar acompanhando essa pluralidade, entendendo que as juventudes precisam ser vistas de modo transversal, mas articulando e integrando uma rede de proteção e promoção sólida para os jovens. Por outro lado, chama atenção o fato de que a maioria das secretarias apresentadas é responsável por apenas 1 programa com enfoque juvenil (apenas STDS e SEDUC apresentaram mais de um programa sob seu comando), assim, incluir mais programas poderá ser algo fundamental para compreender que não 
estamos falando de uma população homogênea, mas de diversos grupos com identidades próprias, isto é, não estamos falando de juventude, mas de juventudes (Abrantes, 2012).

Com base na pesquisa dos programas para as juventudes do PPA 2016-2019, considerando a distribuição segundo os parâmetros estabelecidos por Aquino (2009) e Alves e Barbalho (2014) e utilizando as palavras-chave nos objetivos dos programas como modo de identificação e intepretação, constatamos que os 18 programas com enfoque juvenil se distribuem de modo equitativo entre os grupos Preparatório e de Empoderamento, ao passo que há apenas 1 programa no grupo Ressocialização. Essa configuração reconhece as juventudes como uma categoria social marcada por inúmeras especificidades, constituindo um passo importante para a formulação de políticas públicas adequadas.

No entanto, embora os tipos de políticas ou programas mencionados sejam importantes, ainda existem empecilhos para que os jovens das classes populares os acessem - eles lidam com altos índices de desemprego e violência e com ausência e/ou ineficácia dos aparatos estatais (como creches, postos de saúde, escolas e áreas de estímulo à cultura), que são fatores importantes para a predisposição à delinquência e violência juvenil (Novaes, 2007). Por isso, mostram-se necessárias mais políticas públicas que também atendam aos jovens que vivem à margem da lei e sem acesso a ações socioeducativas eficientes, que promovam um futuro sem exclusão econômica e social.

Mesmo considerando todas as anuências, o PPA 2016-2019 indica que o Governo do Estado do Ceará vem empreendendo esforços não só para preparar os jovens para sua entrada no mercado de trabalho, mas, também, para empoderá-los por meio de programas que concedam garantias básicas e democratizem seu acesso a temas estratégicos (como esporte e cultura). Tal fato deverá contribuir, a longo prazo, para a redução dos números de mortalidade juvenil que apresentamos na introdução deste artigo.

Por fim, vale destacar que o desenho de toda política pública deve ser discutido, formulado e avaliado. Então, futuros estudos podem abordar o grau de modificação que as políticas públicas promoveram, visando a superar as justificativas que ensejaram sua formulação e inserção no PPA 2016-2019 do governo estadual, mas sem deixar de identificar as demandas das juventudes e garantindo os direitos dos quais elas são sujeitos.

\section{Referências bibliográficas}

Abramovay, M. (2002). Juventude, violência e vulnerabilidade social na América Latina: desafios para políticas públicas. Brasília, DF: UNESCO.

Abrantes, M. S. (2012). Juventude e políticas públicas: algumas reflexões. Recuperado de https:// psicologado.com.br/atuacao/politicas-publicas/juventude-e-politicas-publicas-algumas-reflexoes Alves, N. R., \& Barbalho, A. A. (2014). A política pública para juventude em Fortaleza. Revista do Mestrado Profissional em Planejamento em Políticas Públicas, 4(12), 125-145.

CONHECER: DEBATE ENTRE O PÚBLICO E O PRIVADO. 
Aquino, L. M. C. (2009). Juventude como foco nas políticas públicas. In J. A. de Castro; L. M. C. de Aquino, \& C. C. de Andrade (Orgs.), Juventude e políticas públicas sociais no Brasil (pp. 25-39).

Brasília, DF: Instituto de Pesquisa Econômica Aplicada.

Braga, M. A. F., Silva, G. P., \& Martins, S. B. (2012). Violências, homicídios e vitimização juvenil no Brasil: alguns indicativos de suas maiores incidências. In Anais do 150 Encontro de Ciências Sociais do Norte e Nordeste. Teresina, PI.

Ceará (Estado). (2018). Anexo I: Demonstrativo de temas estratégicos e programas (Anexo I a que se refere o art. 1ำ, da Lei n.16.606, 18 de julho de 2018). Fortaleza, CE: Secretaria de Planejamento e Gestão.

Constituição da República Federativa do Brasil, de 5 de outubro de 1988. (1988). Brasília, DF.

Diógenes, G. (2012). Juventudes, violência e políticas públicas no Brasil: tensões entre o instituído e o instituinte. Sinais Sociais, 18(6), 102-127.

Ferreira, M. P., Constantino, A., Souza, G. O. C., Pitta, M. T., \& Dini, N. P. (2010). Identificação das áreas intraurbanas que concentram população jovem vulnerável à violência letal no município de São Paulo: uma proposta metodológica. Revista Brasileira de Segurança Pública, 6(4), 134-144.

Galvão, M. C. B., Pluye, P., \& Ricarte, I. L. M. (2017). Métodos de pesquisa mistos e revisões de literatura mistas: conceitos, construção e critérios de avaliação. Revista de Ciência da Informação e Documentação, 8(2), 4-24.

Gil, A. C. (1991). Como elaborar projetos de pesquisa (3a ed.). São Paulo, SP: Atlas.

Instituto de Pesquisa Econômica Aplicada, \& Fórum Brasileiro de Segurança Pública. (2019). Atlas da violência 2019. Brasília, DF: Ipea.

Guimarães, A. Q., \& Almeida, M. E. (2012). Jovens e o mercado de trabalho. Recuperado de https:// diamantina.cedeplar.ufmg.br/portal/download/diamantina-2012/jovens_e_o_mercado_de_ trabalho.pdf

Lei n. 12.852, de 5 de agosto de 2013. (2013). Institui o Estatuto da Juventude e dispõe sobre os direitos dos jovens, os princípios e diretrizes das políticas públicas de juventude e o Sistema Nacional de Juventude - SINAJUVE. Brasília, DF.

Manfroi, I. (2016, 1ำ de abril). Políticas públicas de ressocialização na gestão do sistema carcerário. Recuperado de https://ambitojuridico.com.br/cadernos/direito-penal/politicas-publicas-deressocializacao-na-gestao-do-sistema-carcerario/

Mantovani, A. L. B. (2009). O papel da sociedade na ressocialização do menor infrator. Recuperado de http://www.ciaap.org.br/artigos/headline.php?n_id=140\&u=1\

Minayo, M. C. S., \& Souza, E. R. (1999). É possível prevenir a violência? Reflexões a partir do campo da saúde pública. Ciência \& Saúde Coletiva, 4(1), 7-32. 
Ministério da Saúde. (2009). A declaração de óbito: documento necessário e importante.

Recuperado de https://www.saude.gov.br/images/pdf/2015/agosto/14/Declaracao-de-Obito-WEB. pdf

Novaes, R. (2007). Juventude e sociedade: jogos de espelhos. Sentimentos, percepções e demandas por direitos e políticas públicas. Revista Sociologia Especial: Ciência e Vida, 1(2), 6-15.

Oliveira, B. I. A. (2019). Diagnóstico da mortalidade juvenil violenta e políticas públicas de prevenção no Estado do Ceará (Monografia de Graduação). Universidade Federal do Ceará, CE.

Oliveira, R. F. V. (2017). O uso do espaço urbano, por meio das políticas públicas de cultura para a juventude: o caso do Centro Urbano de Cultura, Arte, Ciência e Esporte - Cuca Barra, em Fortaleza-CE. In Anais do 30 Seminário Regional Comércio, Consumo e Cultura nas Cidades. Sobral, CE.

Pais, J. M. (1990). A construção sociológica da juventude: alguns contributos. Análise Social, 25 (105106), 139-165.

Semicheche, A., Higa, K. M., \& Cabreira, L. (2012). Protagonismo juvenil: a participação dos jovens para a transformação social. Akrópolis Umuarama, 20(1), 21-38.

Silva, A. M. S., \& Ximenes, V. M. (2019). Políticas públicas e juventude: análises sobre o protagonismo juvenil na perspectiva dos jovens pobres. Pesquisas Práticas Psicossociais, 14(1), 1-15.

Waiselfisz, J. J. (2015). Mapa da violência 2015: adolescentes de 16 e 17 anos do Brasil. FLACSO Brasil. Recuperado de http://flacso.org.br/files/2017/04/mapaViolencia2015_adolescentes-1.pdf

\section{Para citar este artigo}

\section{Norma A - ABNT}

OLIVEIRA, B. I. A.; RACCHUMI, J. A. R. Programas para as juventudes cearenses no Plano Plurianual 2016-2019 do governo estadual. Conhecer: Debate entre o Público e o Privado, v. 10, n. 25, p. 183-201, 2020.

\section{Norma B - APA}

Oliveira, B. I. A. \& Racchumi, J. A. R. (2020). Programas para as juventudes cearenses no Plano Plurianual 2016-2019 do governo estadual. Conhecer: Debate entre o Público e o Privado, 10(25), 183-201.

\section{Norma C - Vancouver}

Oliveira BIA, Racchumi JAR. Programas para as juventudes cearenses no Plano Plurianual 2016-2019 do governo estadual. Conhecer: Debate entre o Público e o Privado [Internet]. 2020 [cited Ago 03, 2020];10(25): 183-201. Available from: https://revistas.uece.br/index.php/revistaconhecer/ article/view/3296 